P. Olszowiec

\title{
MODIFICATIONS OF DIODE RECTIFIER CIRCUITS FOR CONTINUOUS INSULATION MEASUREMENT IN LIVE AC IT NETWORKS
}

Purpose. In the paper there are described few systems of insulation resistance continuous measurement using an imposed DC test signal delivered by diode rectifiers. Drawbacks of this technique are pointed out and ways of these shortcomings removal are proposed. Methodology. An improved version of measuring circuit based on a single-phase diode rectifier is presented. Application of logometric measuring devices is suggested. Results. A new insulation resistance continuous measuring system is insensitive to network voltages variation and asymmetry. Modified circuit enables also implementation of a simple device for alarming the monitored network's insulation deterioration and/or earth-fault protection. Originality. Formulas describing performance of diode rectifiers under asymmetrical supply have not been available so far. Both innovations (i.e. single-phase diode rectifier and logometric meter) have not been applied widely for implementation of continuous insulation monitoring in live AC IT networks. Practical value. Use of both innovations will allow to eliminate unrequired dependence of measurement results on variable network voltages as well as their possible asymmetry. Exploitation of diode rectifier circuits for earth fault location is also possible. References 6, figures 9.

Key words: low voltage AC IT networks, insulation resistance, diode rectifier, insulation resistance decline alarming, earth fault location.

Представлена работа разных вентильных схем измерения сопротивления изоляции сетей низкого напряжения с изолированной нейтралью. Приведены формулы для вычисления эквивалентного сопротивления изоляции при асимметрии линейных напряэений сети. Предложсеы способы устранения недостатков этих схем с использованием однофазных выпрямителей. Показаны возможности реализации системы сигнализации о понижении сопротивления изоляции и поиска места замыкания на землю. Библ. 6, рис. 9.

Ключевые слова: сети низкого напряжения с изолированной нейтралью, сопротивление изоляции, диодный выпрямитель, сигнализация о понижении сопротивления изоляции, поиск места замыкания на землю.

Introduction. Insulation monitoring is indispensable for safe and reliable operation of electric systems. In low voltage unearthed networks wide application has been found by insulation monitors based on diode rectifiers. However in recent years, in spite of numerous qualities of this technology, leading position was taken by isometers exploiting superimposed test signal delivered by an auxiliary source. Most technical literature is devoted to these new methods [1]. Nevertheless it seems useful to remind traditional insulation monitors with rectifier circuits and review possible ways of their improvement.

Problem definition. Main qualities of isometers with diode rectifiers are simple construction, lack of an auxiliary test signal source, fast response, high accuracy and insensitivity to ground capacitances [2]. However these devices have got also few shortcomings limiting their application.

This paper is aimed at analysis of existing measuring systems and schemes improved by author, based on single phase rectifiers.

Existing schemes. Scheme A. The most popular insulation monitoring scheme without an auxiliary test signal source is a system with full-wave bridge rectifier fed by the monitored network (Fig. 1).

A separating transformer is fed by a line-to-line voltage whereas its secondary winding is connected by rectifier and current limiting resistor $R_{0}$ between one of conductors and ground. Rectified current is a test signal for determination of insulation-to-ground equivalent resistance $R_{i}$. Mean value $U_{0 \text {-mean }}$ of voltage across $R_{0}$ resistor

$$
U_{0-\text { mean }}=\sqrt{2} \cdot E_{b c} \cdot \frac{R_{0}}{R_{0}+R_{i}},
$$

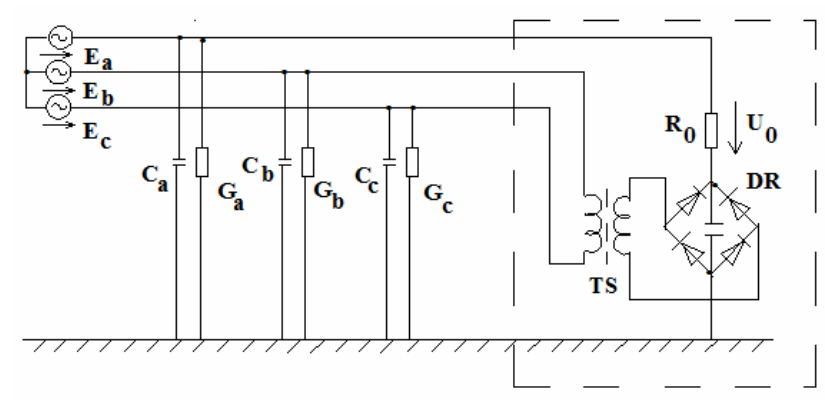

Fig. 1. Scheme A of insulation resistance measurement in a 3-phase network: TS - separating transformer, DR - fullwave bridge rectifier, $\mathrm{R}_{0}$ - current limiting resistor, $E_{a}, E_{b}, E_{c}-$

phase voltages of the source, $C_{a}, C_{b}, C_{c}$ - phase-to-ground capacitances, $G_{a}, G_{b}, G_{c}$ - phase insulation leakage conductances

provides information on the sought parameter $R_{i}$. Its value is given by formula

$$
R_{i}=R_{0} \cdot \frac{\sqrt{2} \cdot E_{b c}-U_{0-\text { mean }}}{U_{0-\text { mean }}} .
$$

The measurement result does not depend on insulation capacitances as mean values of charging and discharging currents are zero. However $R_{i}$ value depends on two voltages at a time $\left(E_{b c}\right.$, and $\left.U_{0}\right)$ which is the main shortcoming of this method. It is worth noting that formula (1) is true at any possible distortion of $U_{0}$ voltage waveform (Fig. 2). 


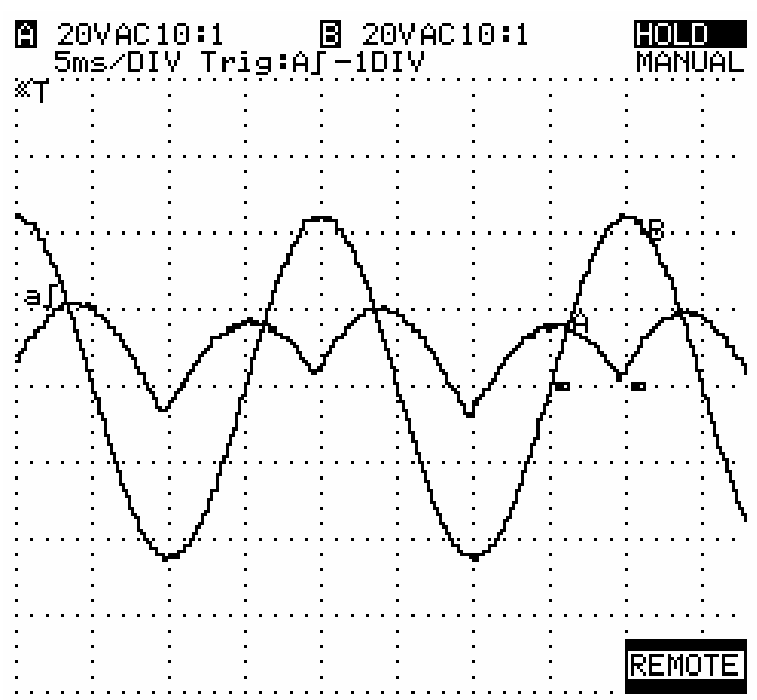

Fig. 2. Waveforms of voltages in scheme A of insulation resistance measurement in a 3-phase network (example): A - voltage $U_{0}, \mathrm{~B}$ - phase-to-phase voltage

Scheme B. Measurement scheme B (Fig. 3) ensures continuous insulation monitoring too. Capacitor $C$ is periodically charged by phases $B$ and $C$ through diode $D$. When the diode is blocked, the capacitor discharges through elements connected in series: current limiting resistor $R_{0}$ and network insulation leakage resistances.

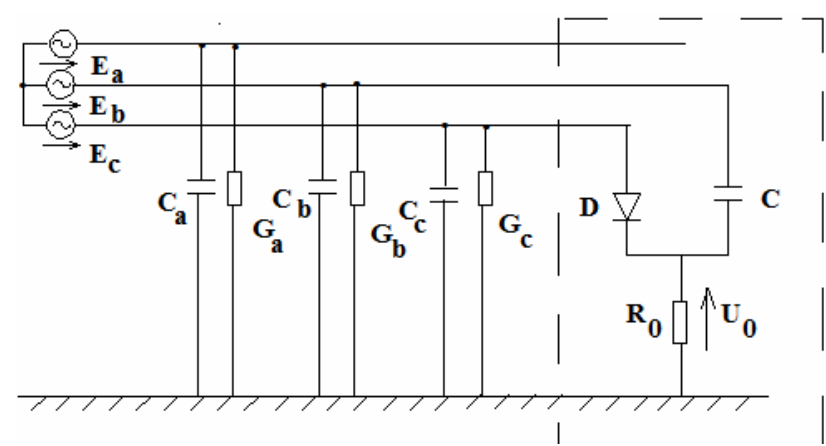

Fig.3. Scheme B of insulation resistance measurement in a 3-phase network: $\mathrm{D}$ - diode, $\mathrm{C}$ - capacitor, $\mathrm{R}_{0}$ - current limiting resistor

Just as in scheme A mean value $U_{0-\text { mean }}$ of voltage across $R_{0}$ resistor is

$$
U_{0-\text { mean }}=U_{C \text {-mean }} \cdot \frac{R_{0}}{R_{0}+R_{i}},
$$

from where sought parameter $R_{i}$ is obtained

$$
R_{i}=R_{0} \cdot \frac{U_{C-\text { mean }}-U_{0-\text { mean }}}{U_{0-\text { mean }}},
$$

where $U_{C \text {-mean }}-$ mean value of voltage across the capacitor.

Examples of voltages waveforms in this scheme are shown in Fig.4. There is presented periodical process of charging and discharging of the capacitor.

For $C$ and $R_{0}$ meeting condition $C \cdot R_{0}>T(T-$ period of the network voltage), voltage across the capacitor is practically constant. In this case formula (4) is as follows

$$
R_{i}=R_{0} \cdot \frac{\sqrt{2} \cdot E_{b c}-U_{0-\text { mean }}}{U_{0-\text { mean }}} .
$$

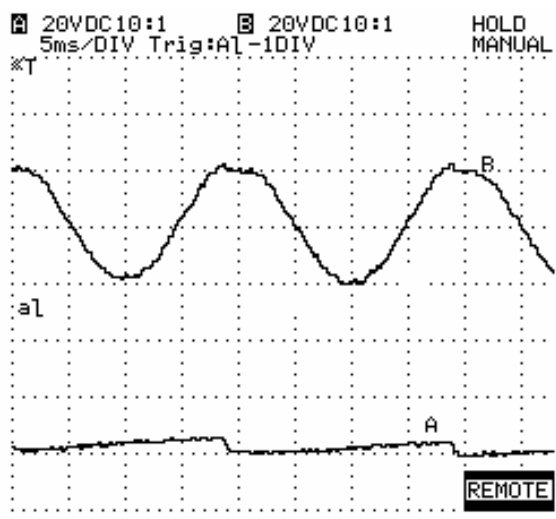

Fig. 4. Waveforms of voltages in scheme $\mathrm{B}$ of insulation resistance measurement in a 3-phase network (example):

A - voltage $U_{0}, \mathrm{~B}$ - phase-to-phase voltage

Scheme C. Three-phase rectifier with star connected diodes belongs to the most popular insulation monitoring systems (Fig. 5) [3].

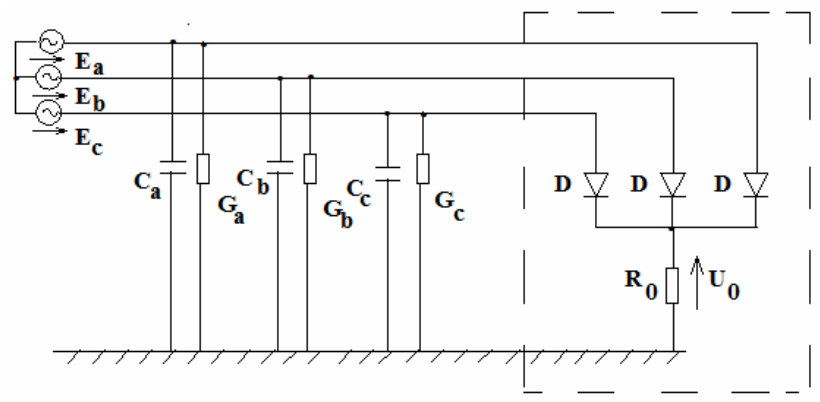

Fig. 5. Scheme $\mathrm{C}$ of insulation resistance measurement in a 3-phase network: $\mathrm{D}$ - diodes, $\mathrm{R}_{0}$ - current limiting resistor

In this scheme there conducts diode with the highest potential of anode. Transition from one diode to another one takes place immediately when their phase voltages become equal.

For derivation of formula determining mean value of $U_{0}$ voltage across $R_{0}$ resistor in a network with asymmetrical source voltages $E_{a}, E_{b}, E_{c}$ it is convenient to use expression for output voltage of a full-wave bridge rectifier (Fig. 6) [4]:

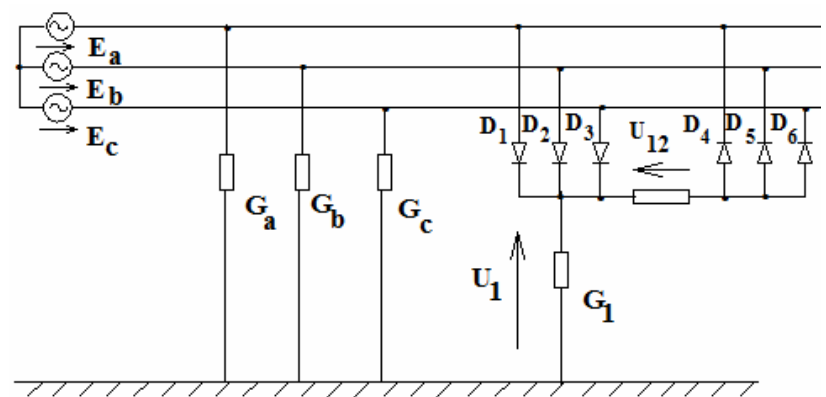

Fig. 6 . Three-phase diode bridge rectifier: $\mathrm{D}_{1} \ldots \mathrm{D}_{6}$ - diodes, $G_{1}$ - insulation leakage conductance of the positive pole

$$
U_{12-\text { mean }}=\frac{\sqrt{2} \cdot\left(E_{a b}+E_{b c}+E_{c a}\right)}{\pi} .
$$

In this system mean value of positive pole-to-ground voltage [5] is

$$
U_{1-\text { mean }}=\frac{G_{i}}{G_{i}+G_{1}} \cdot \frac{U_{12-\text { mean }}}{2} .
$$


From (6) and (7) formula for mean value $U_{0-\text { mean }}$ of voltage across $R_{0}$ resistor in scheme $\mathrm{C}$ is obtained

$$
U_{0-\text { mean }}=\frac{\sqrt{2} \cdot\left(E_{a b}+E_{b c}+E_{c a}\right)}{2 \pi} \cdot \frac{R_{0}}{R_{0}+R_{i}} .
$$

From (8) sought value is derived

$$
R_{i}=\left(\frac{\sqrt{2} \cdot\left(E_{a b}+E_{b c}+E_{c a}\right)}{2 \pi \cdot U_{0-\text { mean }}}-1\right) \cdot R_{0} .
$$

Elimination of shortcomings of schemes A, B, C. Main shortcoming of methods A, B, C (except of lack of self- monitoring) is dependence of calculated parameter $R_{i}$ simultaneously on the network phase-to-phase voltages and on $U_{0}$ voltage. These voltages are of course proportional but when using formulas (2) and (4) their current values must be known. If source voltages vary with time, simultaneous readings of two voltmeters must be made.

Scale of $U_{0}$ voltmeter can be graduated in kOhms only if network voltages are known and do not change.

In scheme $\mathrm{C}$ an additional difficulty can be caused by possible asymmetry of the source voltages. In order to accurately determine $R_{i}$ parameter from formula (9), all three phase-to-phase voltages must be simultaneously measured. The latter obstacle can be overcome by a simple modification proposed by the author.

In a three-phase rectifier with star connected diodes only two diodes fed by any phase-to-phase voltage can be exploited [6] (Fig.7.).

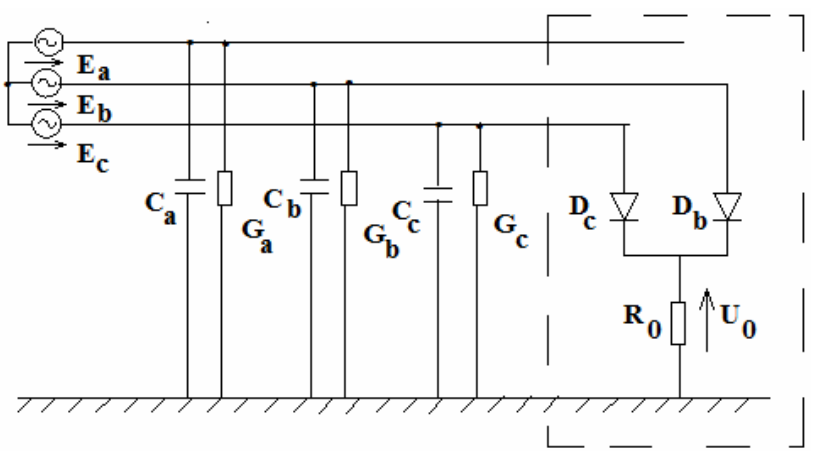

Fig. 7. Modified scheme of insulation resistance measurement with two diodes in a 3-phase network

Let the rectifier be fed by phase $b$-to-phase $c$ voltage,

$$
e_{b c}(t)=e_{b}(t)-e_{c}(t)=\sqrt{2} \cdot E_{b c} \cdot \sin \omega t,
$$

and phase $a$ voltage be determined by function $e_{a}(t)=\sqrt{2} \cdot E_{a} \cdot \sin (\omega t-\alpha)$, where parameters $E_{a}, E_{b c}, \alpha$ can assume any possible value.

Current switchover from one diode to the other one takes place when $e_{b c}(t)$ voltage is zero. Within interval $0<t<T / 2$ diode $\mathrm{D}_{\mathrm{b}}$ is open. According to the I Kirchhoff law leakage currents (to ground) balance is

$$
\begin{aligned}
& \left(G_{b}+G_{0}\right) \cdot u_{0}+G_{c} \cdot\left(-e_{b c}+u_{0}\right)+G_{a} \cdot\left(u_{0}-e_{b}+e_{a}\right)+ \\
& +C_{b} \cdot \frac{d u_{0}}{d t}+C_{c} \cdot \frac{d\left(-e_{b c}+u_{0}\right)}{d t}+C_{a} \cdot \frac{d\left(e_{a}-e_{b}+u_{0}\right)}{d t}=0 . \\
& \text { Within interval } T / 2<t<T \text { diode } \mathrm{D}_{c} \text { is open } \\
& \left(G_{c}+G_{0}\right) \cdot u_{0}+G_{b} \cdot\left(e_{b c}+u_{0}\right)+G_{a} \cdot\left(u_{0}-e_{c}+e_{a}\right)+ \\
& +C_{c} \cdot \frac{d u_{0}}{d t}+C_{b} \cdot \frac{d\left(e_{b c}+u_{0}\right)}{d t}+C_{a} \cdot \frac{d\left(e_{a}-e_{c}+u_{0}\right)}{d t}=0 .
\end{aligned}
$$

Using insulation equivalent parameters of AC side $G_{i}=G_{a}+G_{b}+G_{c}$ and $C_{i}=C_{a}+C_{b}+C_{c}$, both equations assume the following form

$$
\begin{aligned}
& \left(G_{i}+G_{0}\right) \cdot u_{0}+C_{i} \cdot \frac{d u_{0}}{d t}+G_{a} \cdot\left(e_{a}-e_{b}\right)+ \\
& +C_{a} \cdot \frac{d\left(e_{a}-e_{b}\right)}{d t}+G_{c} \cdot\left(-e_{b c}\right)+C_{c} \cdot \frac{d\left(-e_{b c}\right)}{d t}=0 \\
& \quad\left(G_{i}+G_{0}\right) \cdot u_{0}+C_{i} \cdot \frac{d u_{0}}{d t}+G_{a} \cdot\left(e_{a}-e_{c}\right)+ \\
& +C_{a} \cdot \frac{d\left(e_{a}-e_{c}\right)}{d t}+G_{b} \cdot e_{b c}+C_{b} \cdot \frac{d e_{b c}}{d t}=0 .
\end{aligned}
$$

After integrating equation (12) within limits $0<t<T / 2$ and equation (13) within limits $T / 2<t<T$ both equations should be added. As integrals of all capacitive currents over period $T$ are zero and mean value of any sinusoidal function is also zero, the following equation is obtained

$$
\left(G_{i}+G_{0}\right) \cdot \frac{1}{T} \int_{0}^{T} u_{0} d t=\left(G_{i}+G_{0}\right) \cdot U_{0-\text { mean }}=\frac{\sqrt{2} \cdot E_{b c}}{\pi} \cdot G_{i},
$$

from which the final formula follows

$$
R_{i}=\frac{1}{G_{i}}=R_{0} \cdot \frac{\frac{\sqrt{2} \cdot E_{b c}}{\pi}-U_{0-\text { mean }}}{U_{0-\text { mean }}} .
$$

In this method the result depends on voltage $E_{b c}$ of two selected phases. Therefore neither any possible asymmetry of source voltages vectors $\underline{E_{a}}, \underline{E_{b}}, \underline{E_{c}}$ nor number of network's phases play any role.

The main shortcoming of all presented schemes i.e. necessity of simultaneous readings of network voltages and $U_{0}$ voltage can be eliminated with help of a system fulfilling division of two voltages values. Thus for scheme $\mathrm{C}$ there can be used a logometer performing division of voltages $\frac{\sqrt{2} \cdot E_{b c}}{\pi}-U_{0-\text { mean }}$ and $U_{0-\text { mean }}$ supplied to its inputs 1 and 2 (Fig. 8). Therefore its indication corresponds to the value given by formula (15). The other way to avoid the problem is application of stabilized voltage source.

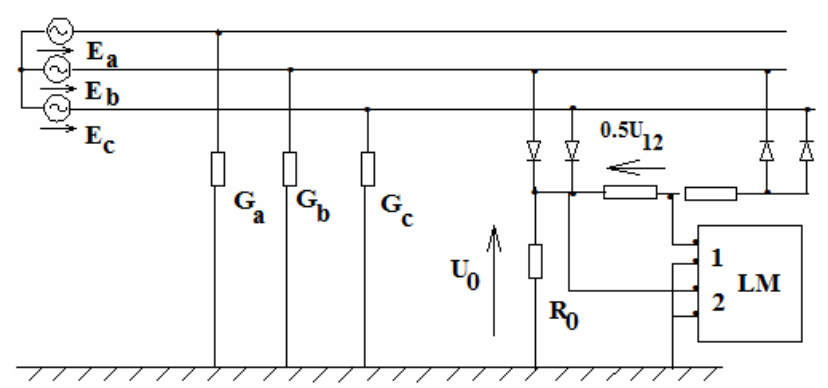

Fig. 8. Application of a logometer $(L M)$ for insulation resistance continuous measurement in a 3-phase network

Additional advantages of A,B,C schemes. All presented schemes of continuous insulation monitoring with diode rectifiers have got few valuable advantages which have not been utilized fully in practice so far.

The first one is implementation of insulation level deterioration alarming. For this purpose a DC overvoltage relay should be connected in parallel with $R_{0}$ resistor. For the relay setting $U_{0-\text { set }}$ it would detect insulation resistance drop below the threshold equal to 


$$
R_{i-s e t}=R_{0} \cdot \frac{E-U_{0-s e t}}{U_{0-s e t}},
$$

where $E$ - voltage of the rectified test current source. For example in the scheme in Fig. 8 this is

$$
E=\frac{\sqrt{2} \cdot E_{b c}}{\pi}=0.5 \cdot U_{12-\text { mean }} .
$$

However a significant shortcoming of this simplest solution is dependence of the alarm threshold on network voltage $(E)$ variation for a fixed relay setting $U_{0-c p}$. Of course this disadvantage can be eliminated with help of a system fulfilling division of voltages or using stabilization of voltage source. Another solution is application of voltage relay supervising sign of the voltages difference

which follows from (16).

$$
U_{0-\text { mean }}-E \cdot \frac{R_{0}}{R_{0}+R_{i-\text { set }}},
$$

The second advantage is possibility for implementation of ground faults location in AC IT networks. Ground faults can be located by measuring rectified test current with help of DC current clamp meter (e.g. Kyoritsu or Fluke). This procedure is illustrated in Fig. 9.

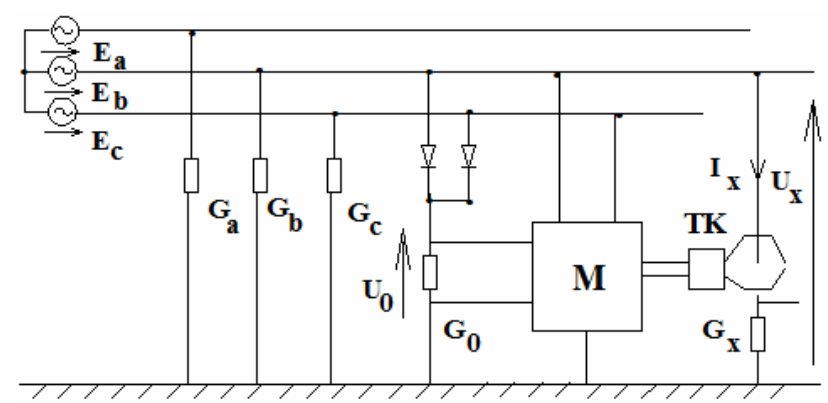

Fig. 9. Application of a scheme of insulation resistance continuous measurement in a 3-phase network for ground fault location:

$M$ - ground fault locator, $T K$ - DC current clamp meter

As mean value of voltage of all conductors against ground is the same, mean values of leakage currents from these conductors to ground are proportional to their insulation-to-ground conductances. When searching for ground fault one can close the clamps around single conductors or multi-wire cables. Microprocessor device $M$ determines equivalent insulation resistance of the entire network from (15) and insulation resistance of a single conductor $\langle\langle x\rangle$ from the following formula

$$
R_{x}=\frac{1}{G_{x}}=\frac{U_{x-\text { mean }}}{I_{x-\text { mean }}}
$$

\section{Conclusions.}

1. Traditional systems of insulation continuous monitoring based on multiphase diode rectifiers are sensitive to variation of network voltages and their possible asymmetry.

2. Application of a single phase star diode rectifier enables to eliminate the above mentioned difficulties.

3. Attention should also be turned to other qualities of the presented schemes i.e. insulation level deterioration alarming and ground fault location.

\section{REFERENCES}

1. Hofheinz W. Protective Measures with Insulation Monitoring. VDE Verlag, 1998.

2. Tsapenko E.F. Kontrol' izoliatsii v setiakh do $1000 \mathrm{~V}$ [Insulation monitoring in networks up to $1000 \mathrm{~V}]$. Moscow, Energiya Publ., 1972. (Rus).

3. Tsapenko E.F. Zamykaniia na zemliu v setiakh 6-35 kV [Earth faults in networks 6-35 kV]. Moscow, Energoatomizdat Publ., 1986. (Rus).

4. Olszowiec P. Unconventional Methods of Analyzing Diode Rectifiers with Asymmetrical Supply. Computational Problems of Electrical Engineering, 2014, no.2, pp. 33-36.

5. Olszowiec P. O wyznaczaniu napięć trójfazowych prostowników diodowych. Wiadomości Elektrotechniczne, 2015, vol.1, no.10, pp. 33-34. doi: 10.15199/74.2015.10.8.

6. Olszowiec P. Insulation Measurement and Supervision in Live $A C$ and DC Unearthed Systems. Lecture Notes in Electrical Engineering, 2nd edition. Springer, 2014. doi: 10.1007/978-3642-29755-7.

Piotr Olszowiec, MSc., Electrical Engineer,

Elporem i Elpoautomatyka Spółka z o.o.,

28-200 Staszow, ul. Wschodnia 10/51, Poland, phone +48 606613976 ,

e-mail: olpio@o2.pl

How to cite this article:

Olszowiec P. Modifications of diode rectifier circuits for continuous insulation measurement in live AC IT networks. Electrical engineering \& electromechanics, 2016, no.2, pp. 43-46. doi: 10.20998/2074-272X.2016.2.08. 